\title{
Synthesis and Characterization of Chromium Doped Zinc Sulfide Nanoparticles
}

\author{
Milind Bodke, Hari Khawal, Umesh Gawai, Babasaheb Dole* \\ Advanced Materials Research Laboratory, Department of Physics, Dr. Babasaheb Ambedkar Marathwada \\ University, Aurangabad, India \\ Email: ${ }^{*}$ drbndole.phy@gmail.com
}

Received 24 April 2015; accepted 13 May 2015; published 20 May 2015

Copyright (C) 2015 by authors and OALib.

This work is licensed under the Creative Commons Attribution International License (CC BY). http://creativecommons.org/licenses/by/4.0/

(c) $\underset{\mathrm{EY}}{\mathrm{C}}$ Open Access

\begin{abstract}
Nanoparticles of pure and $\mathrm{Zn}_{1-\mathrm{x}} \mathrm{Cr}_{\mathrm{x}} \mathrm{S}$ with concentrations $(\mathrm{x}=0.00,0.02,0.08$ and 0.10$)$ were prepared successfully by co-precipitation technique. Crystallographic study was intervened by X-ray diffraction spectroscopy. There were no extra peaks observed in the XRD pattern. From XRD peaks it is confirmed that the samples prepared were highly pure and cubic in structure. The particle size calculated from XRD data was around $3 \mathrm{~nm}$. It confirms that the quantum dots were formed. Surface morphology and crystal size were verified by scanning electron microscopic (SEM) and transmission electron microscopic (TEM) studies. The aggregation of the nanoparticles was observed, which is due to the quantum dots. Chemical species present in the prepared samples were identified by FTIR study. Using UV-Vis spectrometer (Ultra Violet Visible), absorption spectra were obtained for $x=0.00,0.02,0.08$ and 0.1 . It is confirmed from UV-Vis that the detected absorption peaks were shifted towards higher wavelengths. The energy band gap values were estimated using UV-Vis spectrometer and found lying in the range of $3.33 \mathrm{eV}-3.02 \mathrm{eV}$. The energy band gap decreases with increasing $\mathrm{Cr}$ concentrations i.e. the red shift was observed.
\end{abstract}

Keywords

Nanoparticles, Co-Precipitation, Energy Band Gap, Red Shift, Quantum Dots

Subject Areas: Nanometer Materials

\section{Introduction}

$\mathrm{ZnS}$ is one of the most important wide band gap semiconductors from II-VI group elements [1]. Among the most studied host materials for diluted magnetic semiconductor (DMS), it means some magnetic materials with appropriate content doped in semiconducting materials known as (DMS). ZnS is a potential candidate for device

${ }^{*}$ Corresponding author.

How to cite this paper: Bodke, M., Khawal, H., Gawai, U. and Dole, B. (2015) Synthesis and Characterization of Chromium Doped Zinc Sulfide Nanoparticles. Open Access Library Journal, 2: e1549. http://dx.doi.org/10.4236/oalib.1101549 
applications because of its wide band gap of $3.7 \mathrm{eV}$, large exciton binding energy of $40 \mathrm{meV}$, high index of refraction of 2.27 at $1 \mu \mathrm{m}$ and $\mathrm{ZnS}$ has been identified as an excellent host semiconductor for supporting roomtemperature ferromagnetism when doped with a variety of $3 \mathrm{~d}$ transition metalions [2]. It is chemically more stable, nontoxic and environmentally safer than other II-VI compound semiconductors. Hence it finds more potential applications in biological detection [3]. Doping with proper element is widely used as an effective method to tune surface states, energy levels, electrical, optical and magnetic properties of semiconducting materials. The optical and magnetic properties of doped semiconductor nanostructures are sensitive to size, morphology, crystal structure, and effects, which may provide new opportunities for investigation and application of ZnS-based nanomaterials.

The zinc chalcogenides ZnS, ZnSe and ZnTe are semiconductors with zinc blende structure at ambient conditions. The stability of high pressure phases of these zinc chalcogenides $\mathrm{ZnX}(\mathrm{X}=\mathrm{S}$. Se, Te) appears to be more complex. Chalcogenides such as $\mathrm{ZnSe}, \mathrm{ZnS}$ have been widely used as important candidates due to their better chemical stability [4]-[6] for photoluminescence (PL), electroluminescence (EL) and cathodoluminescence (CL) devices. ZnS is one of the most promising luminescent materials among II-VI groups, because it exhibits wide optical transparency from the visible light of $0.4 \mu \mathrm{m}$ to the deep infrared region of $12 \mu \mathrm{m}$. Doped ZnS semiconductor materials have a wide range of applications in phosphors, light emitting displays, optical sensors and also are used in optoelectronic applications such as reflector, dielectric filter and window materials.

Efficient doping of rare-earth ions into II-VI semiconductor host is not favourable compared to the transition metals [5]. In view of this, transition metal doped ZnS, like ZnS:Mn, ZnS:Cu, ZnS:Co and ZnS:Ni has been widely investigated. However, surprisingly, in spite of both applied and academic interest, $\mathrm{Cr}$ doped $\mathrm{ZnS}$ has been least studied. There are only a few reports [7] [8] on Cr doped $\mathrm{ZnS}$ and all these reports are on $\mathrm{ZnS}: \mathrm{Cr}$ prepared by physical methods only. Surprisingly none of the earlier authors have used the chemical synthesis, although chemical route is simple and capable of yielding nanoparticles of higher purity.

In the present study we have chosen chemical co-precipitation route for synthesis of $\mathrm{Cr}$ doped $\mathrm{ZnS}$ nanocrystals because this route is easy to handle and cost-effective and takes less time. It was investigated from XRD; samples were cubic in structure and highly pure. Fourier Transform Infra-Red (FTIR) Spectra confirm that $\mathrm{Cr}$ goes into $\mathrm{ZnO}$ lattice structure. Scanning electron microscopy (SEM) outlines, aggregation of the particles in all samples were observed. It is confirmed from transmission electron microscopic study reports that the crystal size obtained from XRD data and that obtained from TEM study are almost the same, which is around $3 \mathrm{~nm}$. The SAED patterns consist of three concentric sharp rings, which correspond to the (111), (220) and (311) planes of diffraction peaks which belong to cubic structure. In the optical study it is observed that energy band gap decreases from $3.33 \mathrm{eV}$ to $3.02 \mathrm{eV}$ with increasing $\mathrm{Cr}$ concentration; red shift in the band gap is detected. Based on density-function calculations $\mathrm{Cr}$ is theoretically proposed to be a reliable dopant in $\mathrm{ZnS}$ [9]. Such results on $\mathrm{Cr}$ doped and undoped $\mathrm{ZnS}$ nanoparticles are reported in this paper qualitatively and quantitatively.

\section{Materials and Methods}

Samples $\mathrm{Zn}_{1-\mathrm{x}} \mathrm{Cr}_{\mathrm{X}} \mathrm{S}$ nanoparticles were synthesized by chemical co-precipitation route at room temperature. The starting materials were Zinc nitrate, chromium nitrate and sodium sulfide. Chemicals used without further purification were of analytical grade. The chemical used as solvent was methanol. The appropriate amounts of zinc nitrate, chromium nitrate and sodium sulfide respectively were dissolved separately in $100 \mathrm{ml}$ methanol and stirred at room temperature for $2 \mathrm{~h}$. Chromium nitrate solution was added into zinc nitrate and stirred for 20 min. Sodium sulfide solutions then added into as prepared solutions of zinc nitrate and chromium nitrate drop wise with vigorous stirring to get homogeneous solution. Throughout the sample preparation, $\mathrm{pH}-10$ of the solution was maintained. The light sky-blue coloured precipitate was obtained; the colour of the precipitate becomes darken as $\mathrm{Cr}$ concentration increases. The precipitate was continuously stirred for $2 \mathrm{~h}$ again to get homogeneous particle size. The precipitate was collected and washed several times by deionised water followed by methanol. The washed precipitate was dried at $50^{\circ} \mathrm{C}$ for 4 hours in the oven and ground for 15 minutes to get $\mathrm{Cr}$ doped $\mathrm{ZnS}$ nanoparticles finally.

\section{Results, Discussion}

\subsection{Structural Study}

The X-ray diffraction (XRD) patterns for pure and $\mathrm{Cr}$ doped $\mathrm{ZnS}$ samples were recorded at room temperature as 
shown in Figure 1. From the peak broadening diffraction it is confirmed that the crystallites were nanosized. The X-ray diffraction patterns of pure and $\mathrm{Cr}$ doped $\mathrm{ZnS}$ nanoparticles were recorded by X-ray diffraction spectrometer (make: Bruker) using $\mathrm{Cu} K_{\alpha}$ radiation $\left(\lambda=1.5406 \AA\right.$ ) with $2 \theta$ ranging $20^{\circ}-80^{\circ}$. The observed diffraction peaks corresponded to (111), (220) and (311) planes are in good agreement with the standard diffraction peaks cubical structure. As well as the d-spacing values and relative intensities of the peaks coincide with the JCPDS data (00-001-0792) of cubic structure. The prepared samples were highly pure because no extra peaks observed in XRD pattern. The lattice parameters, volume cell, X-ray density, grain size were determined using XRD data \& their values are summarized in Table 1.

The (111) diffraction peaks were shifted to higher $2 \theta$ values as $\mathrm{Cr}$ concentration increases into ZnS than pure ZnS sample. It may be due to the small ionic radii of $\mathrm{Cr}^{3+}(0.63 \AA)$ as compared to that of $\mathrm{Zn}^{2+}(0.74 \AA)$, which have entered into ZnS. A. Rahdar [10] reported that the $\mathrm{Cr}$ doped ZnS nanoparticles synthesized by co-precipitation route was wurtzite (hexagonal) structure. But in this present work the XRD pattern is in good agreement

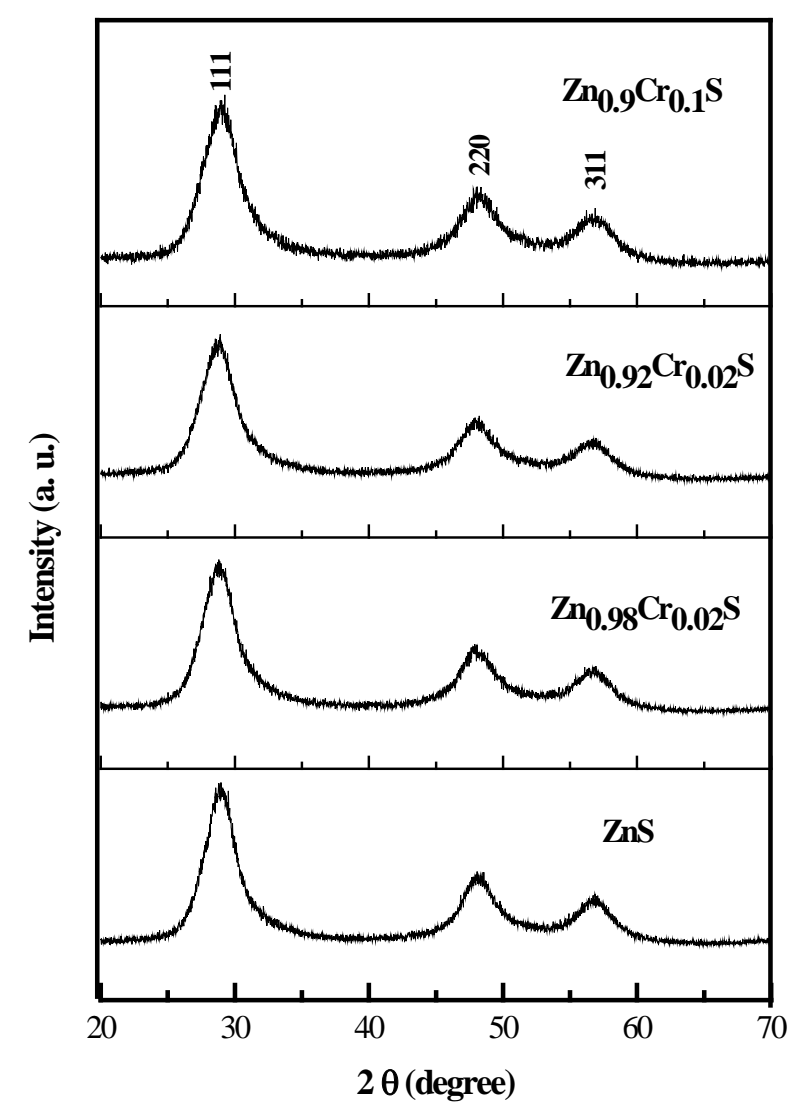

Figure 1. XRD pattern of pure and $\mathrm{Cr}$ doped ZnS nanoparticles.

Table 1. Lattice parameters, volume cell, X-ray density, grain size, \% of crystallinity and \% of amorphous of pure and Cr doped ZnS samples.

\begin{tabular}{ccccccc}
\hline $\begin{array}{c}\text { Cr } \\
\text { Concentration (x) }\end{array}$ & $\begin{array}{c}\text { Lattice } \\
\text { parameter “a” }(\mathbf{n m})\end{array}$ & Volume $(\mathbf{\AA})^{\mathbf{3}}$ & $\begin{array}{c}\text { X-ray density } \\
\left(\mathbf{g m} / \mathbf{c m}^{\mathbf{3}}\right)\end{array}$ & $\begin{array}{c}\text { Grain size } \\
\mathbf{( n m )}\end{array}$ & $\begin{array}{c}\text { \% of crystallinity } \\
\text { \% of amorphous }\end{array}$ \\
\hline 0.00 & 0.53913 & 156.151 & 1.0366 & 3.853 & 57.4 & 42.6 \\
0.02 & 0.53758 & 155.360 & 1.0391 & 3.520 & 57.6 & 42.4 \\
0.08 & 0.53777 & 155.466 & 1.0101 & 3.653 & 57.6 & 42.4 \\
0.10 & 0.53423 & 152.475 & 1.0470 & 3.886 & 56.6 & 43.4 \\
\hline
\end{tabular}


with the diffraction data of cubical structure and the cell parameter "a" is very close to the reported value in JCPDS card data.

Grain size of the nanoparticles was determined by the Debye-Scherrer's equation,

$$
D=\frac{K \lambda}{\beta \cos \theta}
$$

where $K$ is shaping factor and having value 0.9 .

Figure 2 shows the plots (a) lattice constant "a" verses $\mathrm{Cr}$ concentration (b) volume of unit cell verses $\mathrm{Cr}$ concentration (c) X-ray density verses $\mathrm{Cr}$ concentration and (d) grain size verses $\mathrm{Cr}$ concentration. Lattice constant "a" and volume of the unit cell decreases gradually from pure $\mathrm{ZnS}$ to $\mathrm{Cr}$ concentration 0.10 except 0.08 $\mathrm{X}$-ray density increases with $\mathrm{Cr}$ concentration except 0.08 and the average grain size of nanoparticles for $\mathrm{Cr}$ concentration 0.02 is less than pure $\mathrm{ZnS}$, and $\mathrm{Cr}$ concentrations 0.08 and 0.10 as shown in Figure 2.

Two more parameters are recorded by X-ray diffraction spectrometer are crystallinity \% and amorphousness \% of the prepared samples. From these recorded values it is clear that the crystallinity \% is more than the value amorphousness \% of the pure and $\mathrm{Cr}$ doped $\mathrm{ZnS}$ nanoparticles.

\subsection{Morphological Study}

Scanning electron microscopy was employed to get scanning electron micrographs of pure and $\mathrm{Cr}$ doped $\mathrm{ZnS}$
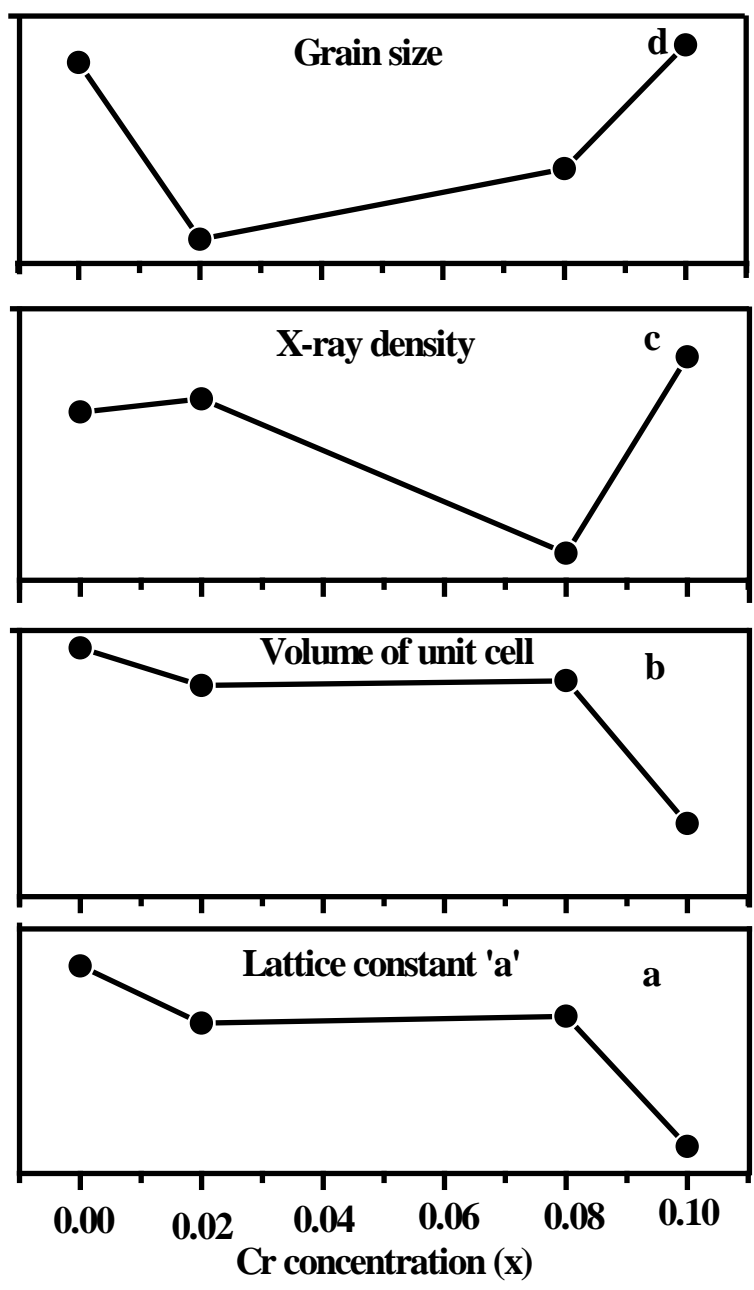

Figure 2. Lattice parameters for pure and $\mathrm{Cr}$ doped $\mathrm{ZnS}$ nanoparticles. 
samples with $5 \mu \mathrm{m}$ magnification as shown in Figure 3. It was clearly seen from SEM images that as synthesized samples exhibit the aggregation of the particles at room temperature. It may be due to the smaller particle size which is around $3 \mathrm{~nm}$. The transmission electron microscopy (TEM) images were obtained using JEOL2010 transmission electron microscope at an acceleration voltage of $200 \mathrm{kV}$ with magnification $2 \mathrm{~nm}$ and $50 \mathrm{~nm}$ for pure and $\mathrm{Cr}$ doped $\mathrm{ZnS}$ nanoparticles as shown in the Figure 4.

The selected area electron diffraction (SAED) patterns for each sample are shown Figure 4. The selected area electron diffraction (SAED) patterns consist of three concentric sharp rings, which corresponded to the (111), (220) and (311) planes of diffraction belong to the cubic structure. Therefore, it can be further confirmed that the

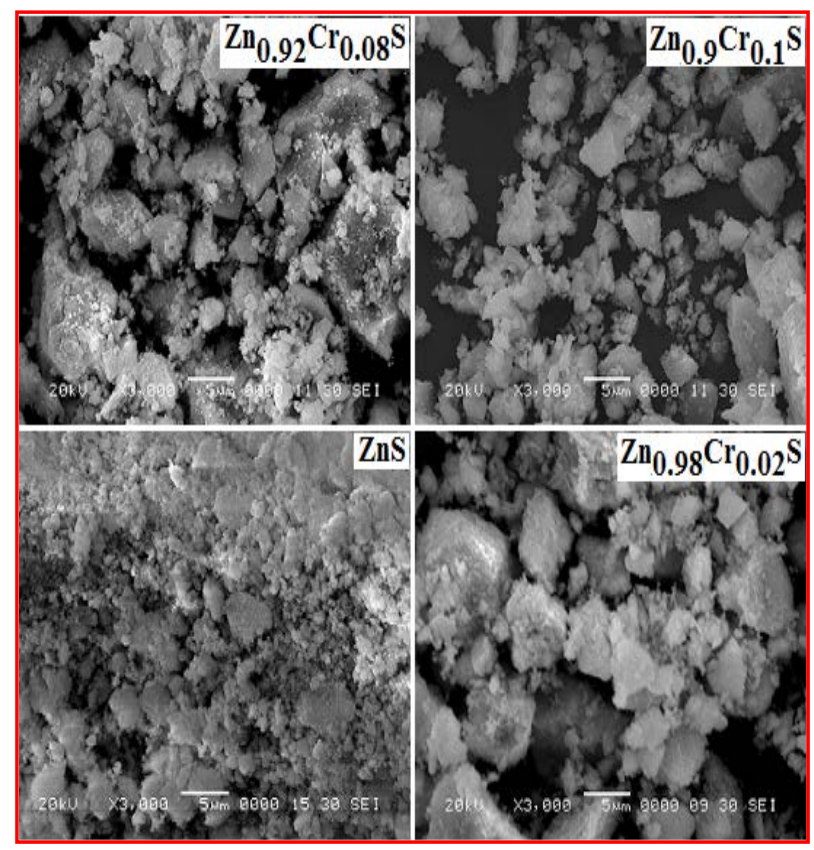

Figure 3. SEM micrographs of pure and $\mathrm{Cr}$ doped $\mathrm{ZnS}$ nanoparticles.

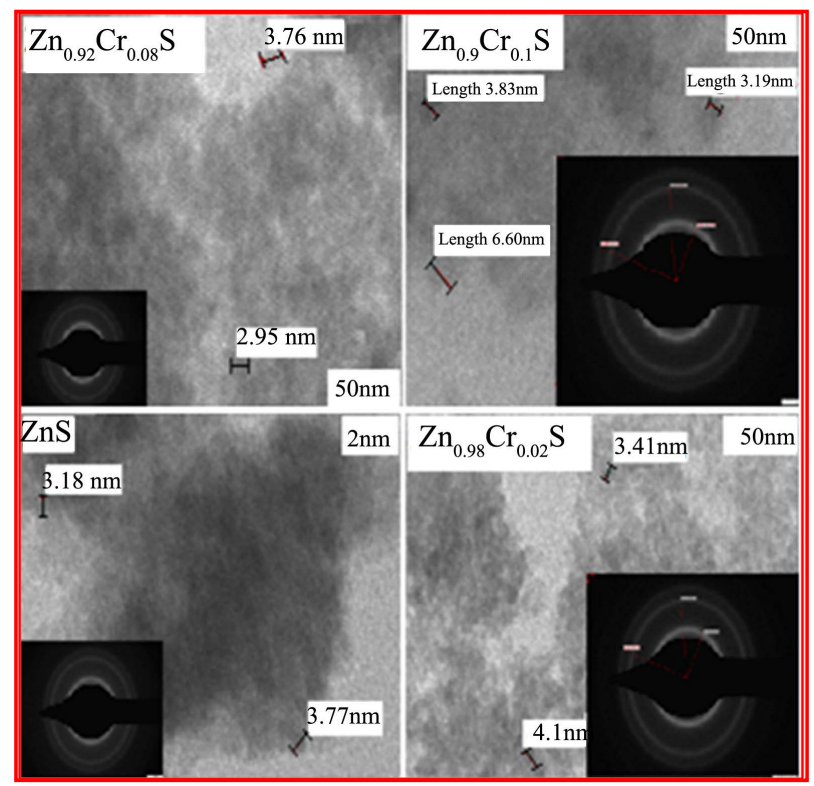

Figure 4. TEM micrographs of pure and Cr doped ZnS nanoparticles. 
nanoparticles are in cubical structure. It is highly confirmed that as synthesized samples are pure and no secondary phases confines. It is found that the $\mathrm{Cr}$ goes to the $\mathrm{ZnS}$ sites. The results from Transmission electron microscopic TEM study are in good agreement with XRD results.

\section{Optical Study}

\subsection{UV-Vis Investigation}

The optical study of pure and $\mathrm{Cr}$ doped $\mathrm{ZnS}$ samples were carried out by ultra violet visible spectrometer. The optical measurements were done with UV spectrometer [Make: JASCO UV-VIS-NIR Spectrophotometer Model: V-670 Serial No. A009761154] in the wavelength range of $200 \mathrm{~nm}$ to $1000 \mathrm{~nm}$. The UV spectra of pure and Cr doped $\mathrm{ZnS}$ samples are plotted. The absorption spectra for pure and $\mathrm{Cr}$ doped $\mathrm{ZnS}$ is as shown in Figure 5. Tauc's plots are as shown in Figure 6. The energy band gap was calculated from the Tauc's plots. The energy band gap values are in the range $3.33 \mathrm{eV}-3.02 \mathrm{eV}$. The band gap increase with increasing $\mathrm{Cr}$ concentration is attributed to size quantization effect due to the smaller size of the particles [11]. In this present work even though the particles are quantum dots the band gap from Tauc's plots of pure $\mathrm{ZnS}$ and $\mathrm{Cr}$ doped $\mathrm{ZnS}$ samples were $3.33 \mathrm{eV}, 3.20 \mathrm{eV}, 3.05 \mathrm{eV}$ and $3.02 \mathrm{eV}$ for Cr concentrations 0.00, 0.02, 0.08 and 0.1respectively. It means

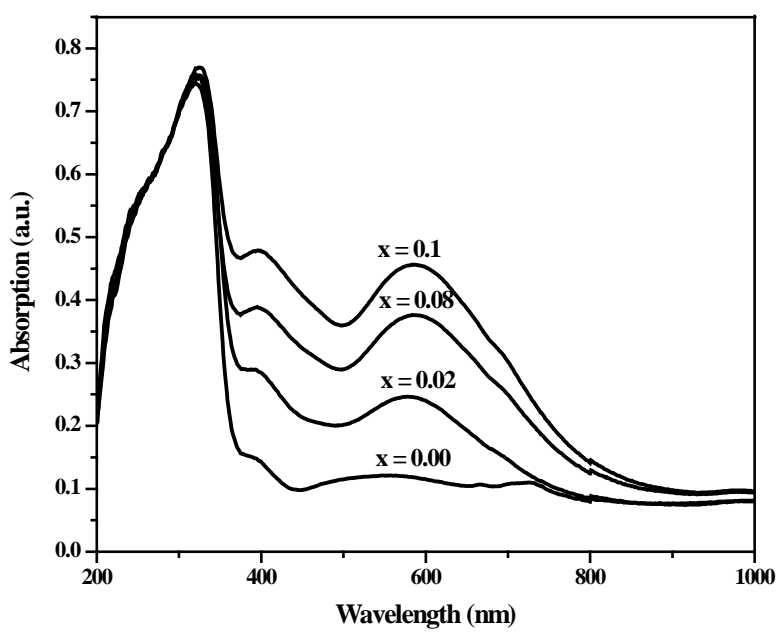

Figure 5. Absorption pattern of pure and Cr doped ZnS nanoparticles.

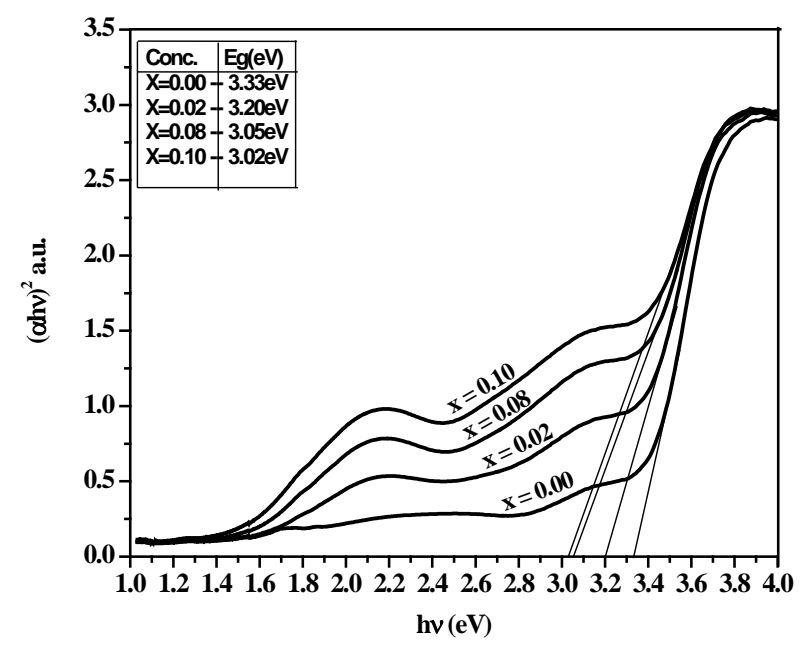

Figure 6. Tauc's plots for pure and $\mathrm{Cr}$ doped ZnS nanoparticles. 
that the band gap decreases with increase in Cr concentration in $\mathrm{ZnS}$ lattice. This is due to the s-p and d interactions and the quantum confinement effect. The red shift in the band gap confirms the uniform substitution of $\mathrm{Cr}$ ions in the $\mathrm{ZnS}$ lattice structure.

\subsection{FTIR Spectra Analysis}

Identifying the absorbed species into the crystal surface and to confirm the formation of crystalline $\mathrm{ZnO}$ nanoparticles Fourier transform infrared spectroscopy study was carried out. FTIR (Make: JASCO FTIR, JAPAN) spectra were recorded at room temperature to obtain information about the chemical bonding and chemical species in a material. FTIR absorption spectra of pure and $\mathrm{Cr}$ doped $\mathrm{ZnO}$ nanoparticles are as shown in the Figure 7 and the peak values are listed in the Table 2.

Broad bands around $3444 \mathrm{~cm}^{-1}$ and $3480 \mathrm{~cm}^{-1}$ appear typically due to $\mathrm{O}-\mathrm{H}$ vibrations of EDTA and water, because all FTIR spectra were carried out by mixing samples with $\mathrm{KBr}$, some water vapour may be absorbed as $\mathrm{KBr}$ is hygroscopic. The additional weak bands and shoulders are observed at $1626 \mathrm{~cm}^{-1}$ and $1639 \mathrm{~cm}^{-1}$ it may be due to micro structural formation of the samples. The C-H bending of methylene in ME is observed at 1407 $\mathrm{cm}^{-1}$ band. The spectra at $1149 \mathrm{~cm}^{-1}$ and $1141 \mathrm{~cm}^{-1}$ were observed, it due to characterization size frequency inorganic ions. The bands $1011 \mathrm{~cm}^{-1}$ and $1040 \mathrm{~cm}^{-1}$ observed due C-O stretching. The spectra at $657 \mathrm{~cm}^{-1}$ and

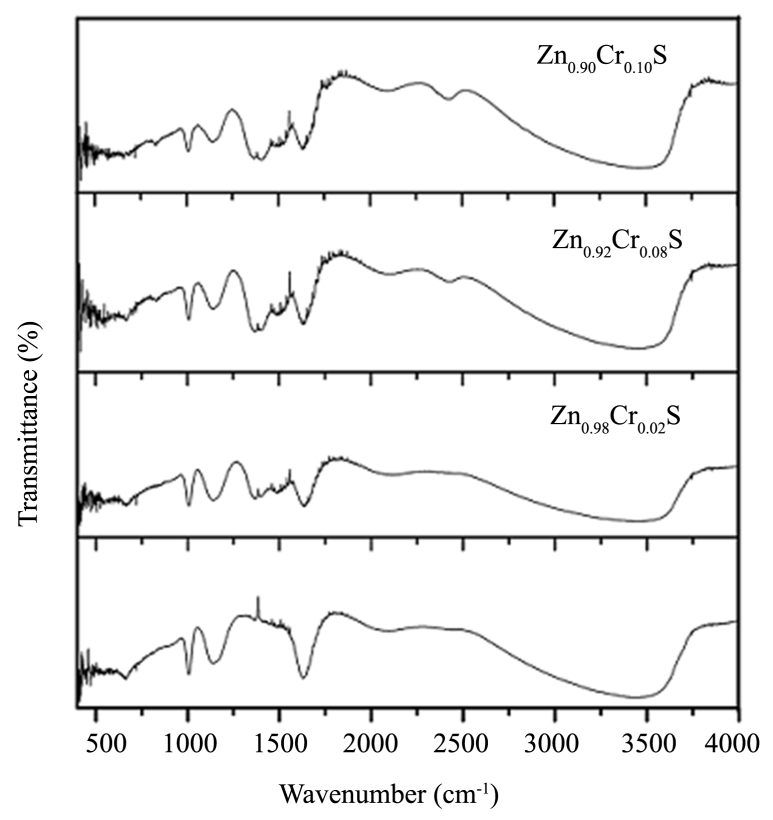

Figure 7. FTIR spectra for pure and Cr doped ZnS nanoparticles.

Table 2. FTIR peaks observed pure and Cr doped ZnS nanoparticles.

\begin{tabular}{|c|c|c|c|c|}
\hline FTIR peaks observed & $X=0.00$ & $X=0.02$ & $\mathrm{X}=\mathbf{0 . 0 8}$ & $X=0.1$ \\
\hline OH-vibrations & 3444.36 & 3457.47 & 3455.30 & 3480.313 \\
\hline $\mathrm{CO}_{2}$ mode & - & - & - & 2103.36 \\
\hline Additional weak bands & 1626.22 & 1626.22 & 1630.51 & 1639.68 \\
\hline C-H bending & - & 1366.313 & 1365.636 & 1407.78 \\
\hline Inorganic ions & 1141.17 & 1141.17 & - & 1149.24 \\
\hline CO stretching & 1011.09 & - & 1013.11 & 1040.52 \\
\hline ZnS band & 657.14 & 657.14 & 668.70 & - \\
\hline
\end{tabular}


$668 \mathrm{~cm}^{-1}$ are ZnS bands that correspond to sulfide. One extra band observed in FTIR spectra for Cr concentration 0.10 at $2103 \mathrm{~cm}^{-1}$ assigned due to $\mathrm{CO}_{2}$ mode, it may be due to the $\mathrm{CO}_{2}$ absorbed from atmosphere while doing FTIR measurements. FTIR spectra of the pure and 10\% Cr doped ZnS nanoparticle samples of present investigation are in good agreement with the reported literature [8] [9] [12] [13].

\section{Conclusion}

Cr doped ZnS nanocrystals were prepared using co-precipitation route successfully. No extra phases were observed in XRD patterns. The samples were cubic in structure and highly pure; it is confirmed from XRD study. From FTIR study it is intervened that the prepared samples were highly pure. The aggregation of the particles in all samples was observed form scanning electron microscopy. From transmission electron microscopic study it is reported that the crystal size obtained from XRD data and that obtained from TEM study are almost the same, which is around $3 \mathrm{~nm}$. The SAED patterns consist of three concentric sharp rings, which correspond to the (111), (220) and (311) planes of diffraction peaks which belong to cubic structure. In the optical study it is observed that energy band gap decreases from $3.33 \mathrm{eV}$ to $3.02 \mathrm{eV}$ with increasing $\mathrm{Cr}$ concentration; red shift in the band gap is detected.

\section{References}

[1] Furdyna, J.K. (1988) Diluted Magnetic Semiconductors. Journal of Applied Physics, 64, R29. http://dx.doi.org/10.1063/1.341700

[2] Biswas, S. and Kar, S. (2008) Fabrication of ZnS Nanoparticles and Nanorods with Cubic and Hexagonal Crystal Structures: A Simple Solvothermal Approach. Nanotechnology, 19, Article ID: 045710. http://dx.doi.org/10.1088/0957-4484/19/04/045710

[3] Peng, W.Q., Qu, S.C., Cong, G.W., Zhang, X.Q. and Wang, Z.G. (2005) Optical and Magnetic Properties of ZnS Nanoparticles Doped with $\mathrm{Mn}^{2+}$. Journal of Crystal Growth, 282, 179-185. http://dx.doi.org/10.1016/j.jcrysgro.2005.05.005

[4] Wang, H., Lu, X., Zhao, Y. and Wang, C. (2006) Preparation and Characterization of ZnS:Cu/PVA Composite Nanofibers via Electrospinning. Materials Letters, 60, 2480-2484. http://dx.doi.org/10.1016/j.matlet.2006.01.021

[5] Rahdar, A. (2013) Effect of 2-Mercaptoethanol as Capping Agent on ZnS Nanoparticles: Structural and Optical Characterization. Journal of Nanostructure in Chemistry, 3, 10. http://dx.doi.org/10.1186/2193-8865-3-10

[6] Shridevi, D. and Rajendran, K.V. (2010) Enhanced Photoluminescence of ZnS Nanoparticles Doped with Transition and Rare Earth Metallic Ions. Chalcogenide Letters, 7, 397-401.

[7] Sarkar, R., Tiwary, C.S., Kumbhakar, P., Basu, S. and Mitra, A.K. (2008) Yellow-Orange Light Emission from Mn ${ }^{2+}-$ Doped ZnS Nanoparticles. Physica E, 40, 3115. http://dx.doi.org/10.1016/j.physe.2008.04.013

[8] Martyshkin, D., Fedorov, V., Kim, C., Moskalev, I.S. and Mirov, S.B. (2010) Mid-IR Random Lasing of Cr-Doped ZnS Nanocrystals. Journal of Optics, 12, Article ID: 02400. http://dx.doi.org/10.1088/2040-8978/12/2/024005

[9] Ichino, K., Morimoto, Y. and Kobayashi, H. (2006) Molecular Beam Epitaxy and Structural Properties of ZnCrS. Physica Status Solidi C, 3, 776-779. http://dx.doi.org/10.1002/pssc.200564699

[10] Rahdar, A., Eivari, H.A. and Sarhaddi, R. (2012) Study of Structural and Optical Properties of ZnS:Cr Nanoparticles Synthesized by Co-Precipitation Method. Indian Journal of Science and Technology, 5, 1855-1858.

[11] Amaranatha Reddy, D., Murali, G., Vijayalakshmi, R.P. and Reddy, B.K. (2011) Room-Temperature Ferromagnetism in EDTA Capped Cr-Doped ZnS Nanoparticles. Applied Physics A, 105, 119-124. http://dx.doi.org/10.1007/s00339-011-6563-1

[12] Goetz, G. and Schulz, H.J. (1992) Influence of the Impurity Concentration on the Microstructure of Compound Semiconductors-The Example of ZnS:Cr Optical Spectra. Solid State Communications, 84, 523-625. http://dx.doi.org/10.1016/0038-1098(92)90182-9

[13] Jia, X., Qin, M. and Yang, W. (2009) Magnetism in Cr-Doped ZnS: Density-Functional Theory Studies. Journal of Physics D, 42, Article ID: 235001. http://dx.doi.org/10.1016/0038-1098(92)90182-9 